Volume 8. No. 6, June 2020

International Journal of Emerging Trends in Engineering Research

Available Online at http://www.warse.org/IJETER/static/pdf/file/ijeter20862020.pdf

https://doi.org/10.30534/ijeter/2020/20862020

\title{
Rotary Heat Exchanger with Low Leakage of Coolants in Seals
}

\author{
Andrey Veniaminovich Kostyukov ${ }^{1}$, Givi Guramovich Nadareishvili ${ }^{1}$, Evgeny Vladimirovich Kovalchuk ${ }^{2}$, \\ Ivan Andreevich Chernushich ${ }^{2}$, Andrey Victorovich Kozlov ${ }^{1}$ \\ ${ }^{1}$ Federal State Unitary Enterprise Central Scientific Research Automobile and Automotive Institute "NAMI" \\ (FSUE «NAMI»), Moscow, Russia \\ ${ }^{2}$ Moscow Polytechnic University, Moscow, Russia
}

\begin{abstract}
This work is aimed at efficiency improvement of seals in rotary disc heat exchanger of microturbines. The reasons of initiation of projects aimed at solution to global environmental problems are analyzed, including improvement of microturbine assemblies. The research method in this work is digital simulation of cooling system of carcass of disc rotary heat exchanger, which decreases the maximum carcass temperature to $+430^{\circ} \mathrm{C}$ providing double reduction of thermal deformations of the carcass cheeks-discs and increase in efficiency of seals contacting the cheeks-discs of the heat exchanger carcass. The influence of rigidity and design of carcass on its thermal deformations is analyzed. The design of heat exchanger carcass is proposed characterized by nearly zero thermal deformations and decreasing leakage in heat exchanger seals to values substantially less than $1 \%$.
\end{abstract}

Key words: microturbine, high efficiency, regenerative heat exchanger, seals, deformation reduction.

\section{INTRODUCTION}

Intensive development of project devoted to solution to global environmental issues, in particular involving conversion to hydrogen-based power units, significantly increases the importance of improvement of microturbine assemblies $[1,2,3]$.

The main problem of microturbines is insufficient fuel efficiency in comparison with internal combustion engines.

One of the main possibilities to increase the efficiency of modern microturbines is to increase regeneration rate of their heat exchangers [4-6]. Increased regeneration rate of heat exchanger leads to significant increase of its sizes. Rotary heat exchangers are known as the most compact devices. Designs of rotary heat exchangers with the regeneration rate of $95-97 \%$ are known $[6,7,8]$, whereas steady heat exchangers are mainly characterized by the regeneration rate up to $90 \%$. In particular, the regeneration rate of the superior microturbine regenerator (Capstone) is 86\% [9].
In addition to good compactness, rotary heat exchangers are characterized by simple and inexpensive fabrication, they are nearly unloaded and easily maintained $[10,11]$. Thus, in rotary disc carcass heat exchanger [10, 11], the heat transfer elements (made in the form of grid, steel ribbon in coils, or as a set of flat plates), which are inserted into carcass glasses (buckets), can be easily removed (without any dissembling of microturbine) and cleaned, if necessary.

The main problem of rotary heat exchangers is coolant leakage through seals. This problem is radically solved in disc carcass heat exchangers. In this case, the seals are operated not by heat transferring matrix with sharp edges but by flat planes-cheeks of heat exchanger carcass $[10,11]$. The leakage in seals of such heat exchangers does not exceed $1.5-2 \%[10,11]$. Another possibility to decrease coolant leakages in seals is decrease in thermal deflection of the heat exchanger carcass, which is deflected due to temperature heterogeneity.

\section{OBJECTIVES}

This work is aimed at studying possibilities to decrease thermal deflection of heat exchanger carcass and, hence, increase in efficiency of heat exchanger seals.

The subject of research was the carcass of disc heat exchanger (outer diameter: $600 \mathrm{~mm}$ ) of $50 \mathrm{~kW}$ microturbine.

\section{METHODS}

The carcass of rotary disc heat exchanger is a rigid block element comprised of flat cheeks-disks and thin hexagonal glasses soldered to them (Figure 1). 


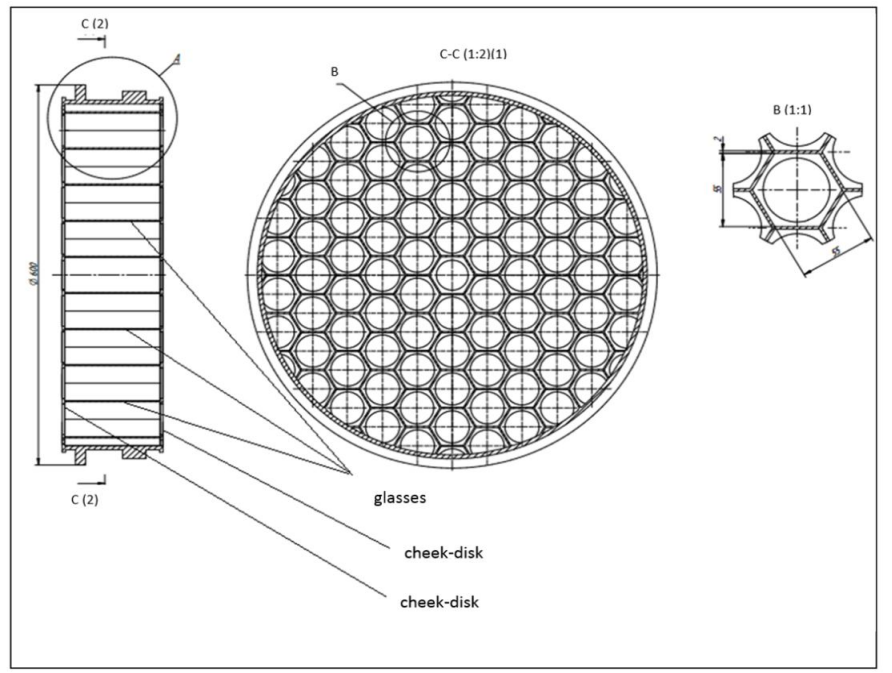

Figure 1: Carcass of rotary disc heat exchanger
In order to decrease thermal deformations of carcass and, respectively, to decrease leakages, the carcass is cooled. Cooling is performed by air passing through the heat exchanger $\left(170-200^{\circ} \mathrm{C}\right)$ and by gas after heat exchanger matrix, thus, cooled (depending on thermodynamic cycle of microturbine and regeneration rate of its heat exchanger, the gas is cooled to $220-270^{\circ} \mathrm{C}$ ). The process and system of carcass cooling are described in details in [12]. Figure 2 illustrates the simulated predictions of thermal and hydraulic processes in rotary heat exchanger with such carcass cooling, namely: distribution of carcass temperature over its width (Figure 3). It can be seen in Fig. 2 that the maximum temperature of heat exchanger carcass does not exceed $700 \mathrm{~K}$ $\left(427^{\circ} \mathrm{C}\right)$.

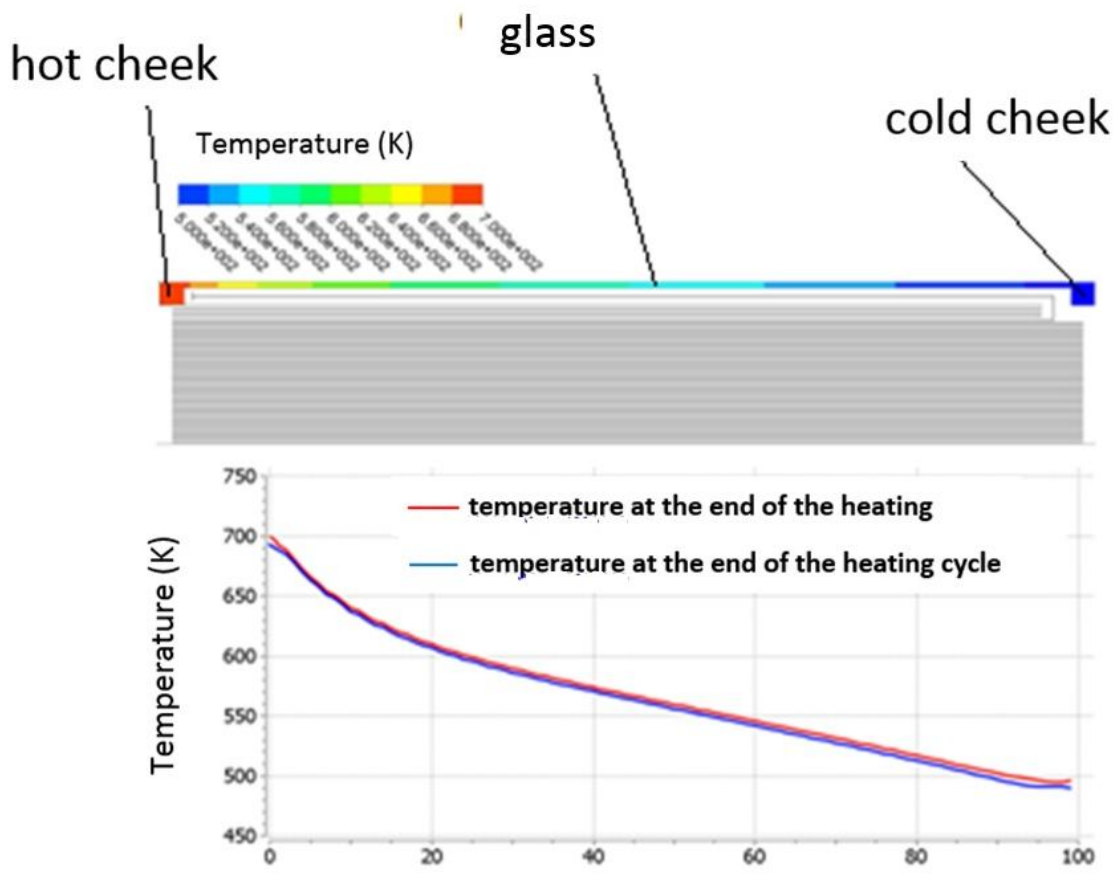

Figure 2: Temperature across the width of the carcass of rotary disc heat exchanger of $50 \mathrm{~kW}$ microturbine

The predictions were made for carcass with coolant flow rate in the cooling system equaling to $3 \%$ of air and gas flow rate across the heat exchanger. Increased sizes of cooling system would lead to even higher decrease in the carcass maximum temperature.

In order to estimate the influence of thermal state of the carcass on its deformation, the thermal deformed state of the heat exchanger carcass was mathematically simulated
[13-15]. The predictions were made for the three cases of carcass maximum temperature: $340^{\circ} \mathrm{C}, 450^{\circ} \mathrm{C}$, and $680^{\circ} \mathrm{C}$ (carcass temperature without cooling). The temperature of cold cheek was considered as the same equaling to $170^{\circ} \mathrm{C}$. In addition to the influence of temperature gradient, the predictions accounted for the influence of wall thickness of carcass glasses, as well as for glasses with individual walls and glasses with common walls (Figure 3). 
Andrey Veniaminovich Kostyukov et al., International Journal of Emerging Trends in Engineering Research, 8(6), June 2020,2327 - 2331

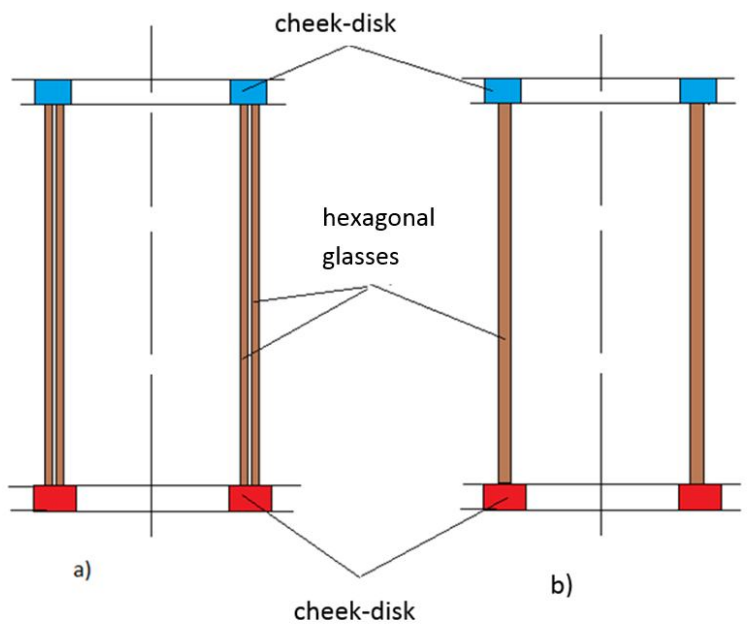

Figure 3: Carcass with separate hexagonal glasses (a) and carcass with glasses (with common walls) (b)

\section{RESULTS AND DISCUSSION}

The calculated data are illustrated in Figure 4.

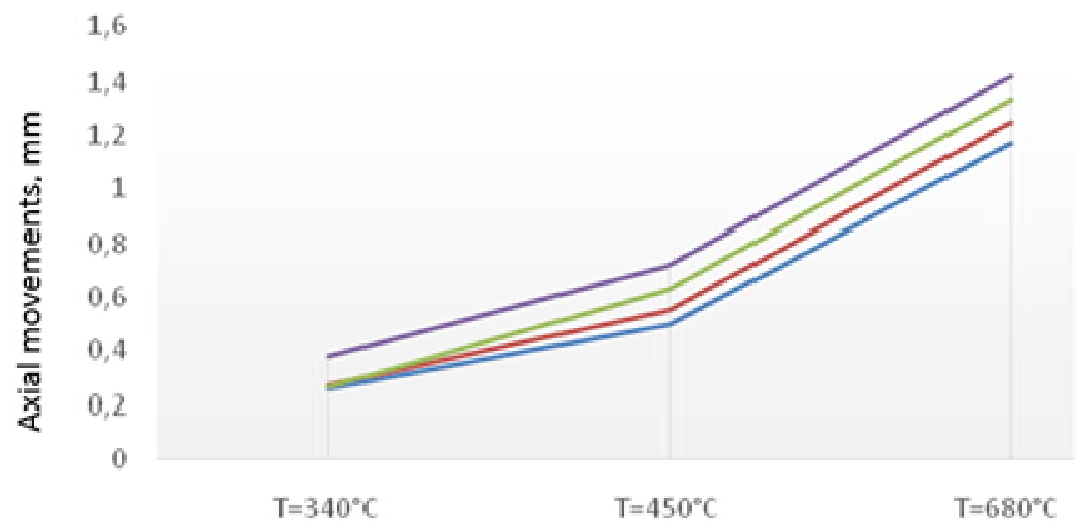

Maximum temperature of carcass (hot cheek of carcass)

Figure 4: Maximum deformations (displacements) of cheeks-discs of heat exchanger carcass along the axis of rotation of heat exchanger (carcass):

- carcass with separate glass walls and wall thickness of $0.4 \mathrm{~mm} ; \quad$ - carcass with separate glass walls and wall thickness of $0.8 \mathrm{~mm} ; \quad-$ carcass with glasses with common walls and wall thickness of $0.8 \mathrm{~mm}$; - carcass with glasses with common walls and wall thickness of $1.6 \mathrm{~mm}$.

As can be seen in Figure 4, deformations of the carcass cheeks-discs decrease significantly with its maximum temperature. Thus, the deformation of carcass cheeks-discs decreases by two times upon decrease in the maximum temperature of carcass from $680^{\circ} \mathrm{C}$ (the maximum temperature of noncooled carcass) to $450^{\circ} \mathrm{C}$. Deformation of cheeks slightly decreases with decrease in the glass wall thickness (decrease in glass rigidity), as well as in the case of separate glasses, that is, with their own walls.

Nearly complete elimination of thermal deflection of carcass occurs in the case of separate glasses, rigid joint (welding, soldering) of glasses with hot cheek-disc and joint of glasses with cold cheek-disc across a layer of high-temperature silicone glued with the cheek and the glasses (Figure 5). 


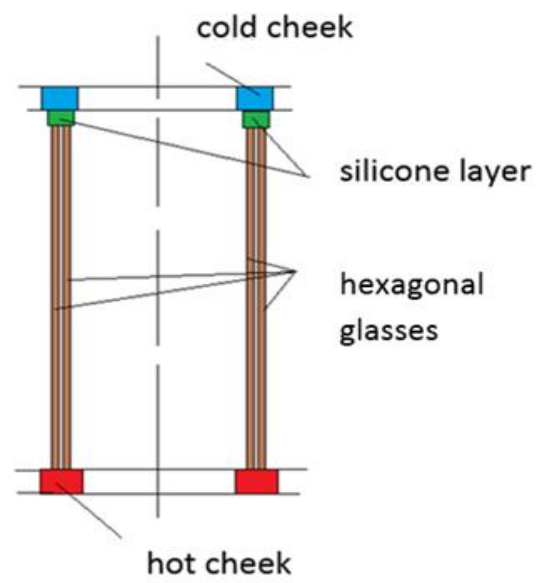

Thermal deformation predictions of such silicone layer with the thickness of $4 \mathrm{~mm}$ and temperatures of hot and cold cheeks-discs equaling to $450^{\circ} \mathrm{C}$ and $170^{\circ} \mathrm{C}$, respectively, are shown below.

As follows from the predictions in Fig. 6, the maximum deformations of carcass cheek in the direction of its rotation do not exceed $0.05 \mathrm{~mm}$, which is lower by an order of magnitude than the deformations of cooled carcass.

Figure 5: Carcass with silicone layer between the glasses and the cold cheek-disc.

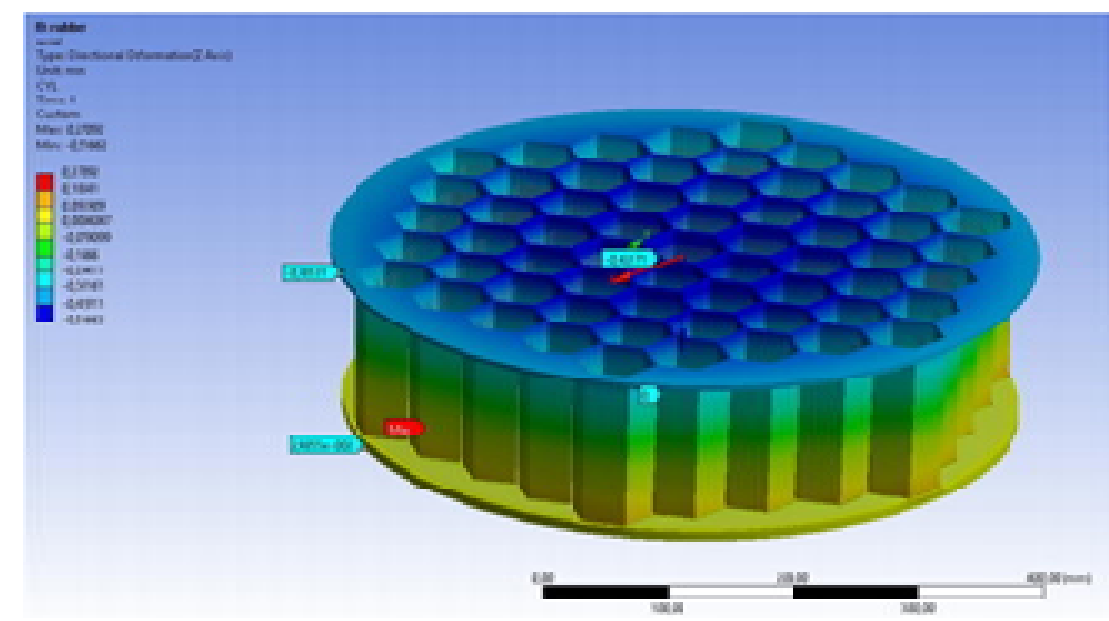

Figure 6: Deformation field of carcass with silicone layer between the glasses and the upper (cold) cheek of carcass along the axis of rotation of heat exchanger

Such small deformations result in significant increase in efficiency of seals of rotary heat exchanger and, finally, in their operation lifetime. In particular, if the coolant leakage is considered to be proportional to the carcass deformation, which in fact is the gap width between the seal frames and cheek-disc of heat exchanger carcass, then it is possible to expect significant decrease in leakages. And if the leakage of well-known rotary disc heat exchanger with cooled carcass $(1.5-2 \%)$ is considered, then the leakage in the heat exchanger with silicone layer and separate glasses in the carcass will by substantially lower than $1 \%$. It should be mentioned that the design of carcass with silicone layer would require for the aforementioned carcass cooling system. This is related with the necessity to obtain the temperature of carcass cold cheek allowable in terms of operability of the silicone layer as well as with the necessity to obtain lower deformations of silicone layer.

\section{CONCLUSION}

The following results have been achieved:

- the considered system of carcass cooling decreases the maximum temperature from $680^{\circ} \mathrm{C}$ to $430^{\circ} \mathrm{C}$;

- deformation of the carcass cheeks-discs along the axis of rotation of heat exchanger decreases twice upon decrease in the maximum temperature of carcass from $680^{\circ} \mathrm{C}$ (the temperature of noncooled carcass) to $450^{\circ} \mathrm{C}$;

- minor decrease in deformations of the carcass cheeks-discs along the axis of rotation of heat exchanger takes place upon decrease in wall thickness of carcass glasses;

- the carcass design is proposed with nearly zero thermal deformations along the axis of rotation of heat exchanger; - the proposed carcass design would decrease coolant leakages in heat exchanger seals to values substantially less than $1 \%$. 
Andrey Veniaminovich Kostyukov et al., International Journal of Emerging Trends in Engineering Research, 8(6), June 2020,2327 - 2331

\section{ACKNOWLEDGEMENT}

This work was supported by the Ministry of Science and Higher Education of the Russian Federation, project \# 075-11-2018-233 (unique identifier RFMEFI62518X0045).

\section{REFERENCES}

1. G.L. Touchton, M. Senkevych, A. Belokon, V. Belyaev, A. Novek. Gas Turbine Product Line for on Site Generation and Combined Heat and Power between 400 kWe AND 1.6Mwe, GT2004-54257, 2004. https://doi.org/10.1115/GT2004-54257

2. Report Volvo - Microturbine Section 1 Volvo. 2005.

3. P. Akbari, R. Nalim, N. Mueller. Performance Enhancement Microturbine Engines Topped With Wave Rotors. Journal of Engineering for Gas Turbines and Power vol. 128 no. 1, 2006.

https://doi.org/10.1115/1.1924484

4. M. Kelly, M.-J. Pan, S. Atre, G. Rancourt, A. Heyes, M. Vick. Ceramic Micro Channel Recuperator Fabrication Methods for Small Gas Turbine Engines, GT2012-68510, 2012.

5. J.L. Cordova, J.F. Walton, H. Heshmat. High Effectiveness, Low Pressure Drop Recuperator for High-Speed and Power Oil-Free Turbogenerator GT2015-43718, 2015. https://doi.org/10.1115/GT2015-43718

6. G. Nadareishvili, A. Kostyukov, K. Karpukhin. Design Features when Using an Effective Microturbine as a Range Extending Engine. Science \& Technique vol. 18 no. 6, pp. 447-460, 2019.

7. D.G. Wilson. The high efficiency of our multistage ceramic-bladed turbine design can produce an attractive economic return even in the absence of CHP. Wilson Solarpower Corporation, 2010.

8. D.G. Wilson, A.C. Pfahnl. A look at the automotive-turbine regenerator system and proposals to improve performance and reduce cost. SAE paper 9270237, Warrendale, PA, 1997.

https://doi.org/10.4271/970237

9. B.F. Kolanovski. BSME. Guide to Microturbines. Printed in the USA, 2004.

10. D.A. Plotnikov. Development and analysis of disc compartment regenerator of vehicle gas turbine engines: cand. thesis. Moscow, 1981.

11. A.V. Kostyukov, A.A. Dement'ev. Vysokotemperaturnyi rotornyi teploobmennik dlya gazoturbinnykh i gerotornykh dvigatelei [High-temperature rotary heat exchanger for gas turbine and gerotor engines]. Izvestiya Moskovskogo gosudarstvennogo tekhnicheskogo universiteta MAMI, vol. 2, no. 12, pp. 23-27, 2011.

12. S.Yu. Eliseev, Yu.S. Kustarev, A.V. Kostyukov, M.A. Krutov. Cooling of carcass of rotary disc heat exchanger and device for its embodiment. RU Patent 2296930, April 10, 2007.

13. A.V. Kozlov, K.E. Karpukhin, A.S. Terenchenko, J.G. Ter-Mkrtichian. Technical and economic assessment of vehicle recycling cost in the Russian Federation. International Journal of Mechanical Engineering and Technology, vol. 8, no. 10, pp. 82-92, 2017.

14. Ter-Mkrtichian, G.G., A.S. Terenchenko and K.E. Karpukhin, 2018. Alternative ways for vehicle ICE development. International Journal of Mechanical Engineering and Technology. Vol. 9, Issue 5, pp. 966-973.

15. K. Karpukhin, A. Terenchenko, A. Kolbasov, V. Kondrashov. The use of microturbines as an energy converter for motor transport. International Journal of Innovative Technology and Exploring Engineering, vol. 8 , no. 10 , pp. $2700-2703,2019$. https://doi.org/10.35940/ijitee.J9451.0881019 